\title{
Knowledge of the community regarding mental health problems: a cross-sectional study
}

Yonas Tesfaye ${ }^{1 *}$, Liyew Agenagnew1, Susan Anand², Gudina Terefe Tucho ${ }^{3}$, Zewdie Birhanu4, Gutema Ahmed', Masrie Getnet ${ }^{5}$ and Kiddus Yitbarek ${ }^{6}$

\begin{abstract}
Background: Knowledge of the community regarding mental health problems has a remarkable impact on the attitude, the help-seeking path, and prevention of stigma and discrimination against patients with mental health problems. It is also the cornerstone for designing evidence-based community mental health interventions. However, the evidence is scarce in developing countries like Ethiopia. This study aimed to assess the knowledge regarding mental health problems and associated factors among communities of Jimma Zone, Oromia, Ethiopia.

Methods: A community-based cross-sectional study was conducted in the Jimma zone from March 1 to 22, 2020. A structured, pretested, and interviewer-administered questionnaire was used to collect data from 420 study participants selected through a systematic sampling technique. The knowledge about mental health was measured by the adapted version of the Mental Health Knowledge Schedule tool. Data were entered into Epi-data version 3.1 and exported to SPSS version 23.0 for analysis. Multivariate logistic regression analysis was done, and $p$-value $<0.05$ and 95\% Cl were used to determine the predictors of the outcome variable.
\end{abstract}

Results: The overall knowledge score showed $(188,44.8 \%)$ of the respondents had inadequate knowledge. Moreover, $(75,17.9 \%)$ of the respondents reported psychiatric disorders are contagious, and (138, 32.9\%) mentioned leaving alone is the treatment for mental illness. Talking or laughing alone and showing strange or unusual behaviors were described as symptoms of mental illness by the majority $(407,96.9 \%)$ and $(403,96.0 \%)$ of respondents, respectively. Brain dysfunction was attributed to the cause of mental illness by most $(390,92.9 \%)$ of the study participants. Similarly, the percentage of responses that attributed the causes of mental illness to possession by an evil spirit, God's punishment, and witchcraft were significantly high $(368,87.6 \%),(321,76.4 \%)$ and $(259,67.1 \%)$, respectively. Furthermore, regression analysis showed that respondents who were able to read and write were $64 \%$ less likely to have adequate knowledge than those in secondary school and above educational status ( $A O R=0.34,95 \% \mathrm{Cl}(0.16-0.69)$ ).

Conclusion: Knowledge of mental illness among the general public was relatively poor and higher levels of education were associated with good knowledge of mental health problems; this suggests the need for due emphasis on public education to improve the mental health literacy status of the community.

Keywords: Knowledge, Perception, Mental health problems, Community, Jimma

*Correspondence: yonastesfaye71@yahoo.com; yonitesfaye71@gmail.com 1 Department of Psychiatry, Jimma University, Po Box 378, Jimma, Oromia, Ethiopia

Full list of author information is available at the end of the article

\section{Background}

Mental health and physical and social health are closely interwoven fibers that are vital for every individual. Mental health extends beyond diagnosed mental disorders. 
According to World Health Organization (WHO) (2002), it encompasses personal well-being, perceived self-efficacy, autonomy, competence, intergenerational dependence, and recognition of the ability to realize one's intellectual and emotional potential [1-4].

Mental health is essential for the overall well-being of individuals, societies, and countries. Despite being imperative for human existence, in many countries, unlike the importance given to physical health, mental health has been relegated. This could partly be due to the myths and misconceptions surrounding mental illnesses in many parts of the world [5-7].

Negative views, fear, and stigmatization are responsible for the ostracization of mentally ill persons and lack of access to proper psychiatric treatment Therefore, mentally ill people seek professional help from hospitals after they have tried all options and the symptom has worsened. This negatively affects the prognoses of treatment $[8,9]$. Mental disorders are attached to negative and stigmatizing attitudes, often due to a lack of knowledge about mental illness $[10,11]$. People with mental illness are perceived as dangerous, unpredictable, and different from others, responsible for their condition, hard to talk to, and incurable in the community [12-14].

The concept of mental health problems and its causes vary in different communities $[5,15]$. Society's knowledge regarding mental illness is often far from the scientific view, and it negatively affects treatment-seeking and adherence [9].

People's perception about mental ailments is influenced by their knowledge, encounters with people suffering from mental illnesses, media portrayal, cultural stereotypes, and their personal experiences of mental disorders $[16,17]$. In many African societies, psychiatric illness is believed to be either an outcome of a familial defect or the 'handiwork of evil machinations' (demons, evil spirits). It is not uncommon to blame psychiatric patients for their illness, especially when it is an alcohol and/or substance-related problem $[18,19]$.

Literature shows Ethiopians, like other sub-Saharan African societies, attribute mental illnesses almost exclusively to supernatural phenomena. Mental illnesses have predominantly been attributed to possession by evil spirits, punishment from God or guardian spirits for sins, and/or curses, spells, or bewitchment by people alleged to have supernatural powers. Research also points out the limited and poorly developed infrastructure for modern mental health services [20-22].

Help-seeking behavior is influenced by people's knowledge of mental health problems and illness, which are based on the combinations of traditional and modern beliefs. Mental health knowledge includes the capacity to identify mental health problems, understanding of risk factors and causes, professional help available, attitudes that promote recognition, and appropriate mental health help-seeking behaviors [23-26].

Often mental illnesses are poorly understood by the general public, which threatens the effectiveness of patient care and rehabilitation [27, 28]. Beliefs about the causation and experience may influence patients' beliefs about effective treatment and may also determine the type of treatment that is sought. At times, the mentally ill are blamed for bringing on their illness. In contrast, others may see mentally ill people as victims of unfortunate fate, religious and moral transgression, or even witchcraft [29]. These misbeliefs may lead to denial of the problem by both the sufferers and their families, with subsequent delays in seeking professional treatment [28, 30-32].

Scientific evidence demonstrates that low rates of seeking psychiatric help are mainly due to inadequate knowledge of mental health disorders, including mental disorders symptoms, and psychiatric treatments [33]. Evidence revealed improved knowledge about mental health and illness leads to less stigma [34-36].

Heterogenous causation of biological, psychological, social, and cultural causes of mental illness was reported from the studies done in Nigeria [37-39], northern Ethiopia [13], and Denmark [40]. Whereas biological factors were reported as the main causes of mental illness in the studies conducted in Tanzania [41], Eretria [38], and Saudi Arabia [42]. Conversely, in South Africa [43], elsewhere in Ethiopia [44-46], Nigeria [36], and, Pakistan [47] mental illness was attributed to religious and cultural factors,

While a combination of medical, religious, and traditional treatment was favored by the respondents in the studies done in Eritrea [48], Saudi Arabia [49], Nigeria [39], and Ethiopia [5], medical management (medication and counseling) was the most preferred among the study subjects in Tanzania [41], Saudi Arabia [42], Slovak Republic, and Russia [50], New Zealand [51], South Africa [43], Ethiopia [13, 52], and India [45].

Overall, inadequate mental health knowledge of the community was described in various studies conducted in many parts of the world $[9,28,30,37,38,40,41,53-$ 55]. The differences in the explanation of the causation and management of mental illness could be due to the difference in the literacy status, socio-cultural-economic disparities, availability, and use of media, and the difference in the availability of mental health services among the countries.

To the best of our knowledge, only a few studies were conducted regarding the rural communities' understanding of mental health problems in Ethiopia. The previous studies were done a long time ago, with fewer sample size, and conducted in different geographical-socio-cultural 
contexts $[9,44,46,56]$. Hence, assessing the community's knowledge is essential in designing an appropriate mental health promotion and scaling up the public's utilization of mental health services. Therefore, the present study aimed to assess the knowledge and associated factors of the Jimma zone community towards mental health and mental health problems.

\section{Methods and materials Study setting and period}

The study was conducted in Jimma zone, Seka chekorsa district. Jimma zone is divided into 20 districts and one town administration. The total population of the zone was 3,209,127 in 2017 [57]. There are four primary hospitals, 20 health centers, and 117 health posts [39] in the zone. A total of 1024 health extension workers are serving the population of this area. Seka chekorsa district is located $20 \mathrm{~km}$ from Jimma town, and the district has 30 kebeles (lowest administrative division) with a total population of 208,096 [58]. This district is resourced with a primary hospital, nine health centers, and 35 health posts. The study was conducted from March 1 to 22, 2020.

\section{Sample size}

The sample size was calculated by using a single population proportion formula. We have taken the estimated proportion of community knowledge regarding mental health problems 50\%, 95\% confidence level, 5\% margin of error. Accordingly, $\mathrm{n}=(\mathrm{z \alpha} / 2)^{2} \mathrm{P}(1-\mathrm{p}) / \mathrm{d}^{2}$. Calculating the sample size $\mathrm{n}=(1.96)^{2} \times 0.5(1-0.5) /(0.05)^{2}$ become 384 . Finally, with the addition of a $10 \%$ contingency for non-response, the final sample size was 423 households.

\section{Sampling procedures}

A community-based quantitative cross-sectional survey was conducted. First, the Seka chekorsa district was selected from 20 districts in the zone through a lottery technique. Out of the 30 kebeles in this district, nine were determined by lottery method based on the World Health Organization (WHO) sample size calculation guideline in the district health system [59]. The proportional allocation determined the number of sampled respondents from each kebele to the total number of households in each selected kebeles. Systematic random sampling technique was used to select the study units, and periodic interval $(\mathrm{K})$ was calculated using the formula $K=N / n$, whereby $N$ is the total households in the selected kebeles (1555), and $\mathrm{n}$ is the estimated sample size (423). Accordingly, every four households were included in the study. The first study unit was selected by a lottery method between the 1st and 4th households. Finally, randomly selected household members aged 18 and above and living in the district for six months or more were interviewed.

\section{Inclusion and exclusion criteria}

All the study community members age 18 and above and living in the district for six months or more were included in the study. Community members with acute or chronic illnesses which would interfere with providing accurate information were excluded.

\section{Measurements and procedures}

The questionnaire consisted of sociodemographic and mental health knowledge questions. The knowledge of the community regarding mental health problems was measured by the adapted version of the Mental Health Knowledge Schedule (MAKS) with a "Yes" or "No" response (Additional file 1). The survey tool has good reliability and validity across many works of literature [60-62]. The reliability, Cronbach alpha score of the scales in this study was 0.66 . The median score was calculated for knowledge-related questions. A cutoff point below and above the median score was considered to estimate the proportion of the community with adequate and inadequate knowledge. Twenty-three health extension workers collected data after getting training for two days on the questionnaire's content, data recording, and the ethical principles of data collection. The data were obtained through a face-to-face interviewer-administered questionnaire prepared in English and translated into Afaan Oromo, and back-translated to English to ensure its consistency by blinded language experts. The translation was face validated by two independent external experts in the field. Moreover, the questionnaire was pre-tested on $5 \%$ of the population in another district to check the impending problems of the data collection tool.

\section{Statistical analysis}

The collected data were cleaned, coded, entered into Epi Data version 3.1, and exported to SPSS version 23 for analysis. Descriptive statistics were done to summarize the dependent and independent variables. The logistic regression analysis model was used to identify the factors associated with the outcome variable; first Bivariate logistic regression was done, and variables with a $p$-value $<0.25$ were selected as candidate variables for multivariate logistic regression analysis. Multicollinearity and Lemeshow-Hosmer test of model fitness test was done before the final model. Then, variables with $P$-value $<0.05$ and $95 \%$ confidence interval odds ratio were considered factors associated with the outcome variable. 


\section{Results}

Socio-demographic characteristics

A total of 420 study participants were interviewed successfully, giving a response rate of $99.3 \%$. The mean age of the respondents was $37.2(\mathrm{SD} \pm 11.9)$ with a range of 18 to 80 years. Most of the study participants were females (230, 54.8\%), married $(345,82.1 \%)$, from rural residence (253, 60.2\%). Additionally, most of the study participants were from the Oromo ethnic group $(395,94 \%)$ and Muslims $(384,91.4 \%)$. The mean family monthly income was 1562.5 Ethiopian Birr (ETB) (SD \pm 2769.8$)$ (Approximately $\$ 48.00 \mathrm{US})$, and most respondents were unable to read and write $(168,40 \%)$ (Table 1$)$.
General knowledge of the respondents regarding mental health problems

Almost all $(404,96.2 \%)$ of the study participants knew psychiatric disorders are a kind of medical disorder, and the majority $(362,86.2 \%)$ recognize psychiatric disorders as treatable. On the contrary, $(75,17.9 \%)$ of the study participants reported psychiatric disorders are contagious, and $(138,32.9 \%)$ described leaving alone as a treatment for mental illness. Additionally, $(155,36.9 \%)$ of the respondents were rejected that mental health problems are identical for males and females. Talking or laughing alone and showing strange or unusual behaviors were reported as the major symptoms of mental illness by

Table 1 Sociodemographic characteristics of respondents at Jimma Zone, Seka woreda South-west Ethiopia, March 2020

\begin{tabular}{|c|c|c|c|}
\hline Variables & Characteristics & Frequency & Percentage \\
\hline \multirow[t]{2}{*}{ Sex } & Male & 190 & 45.2 \\
\hline & Female & 230 & 54.8 \\
\hline Age & $37.2(\mathrm{SD} \pm 11.9)$ Range 18 to 80 years & & \\
\hline \multirow[t]{2}{*}{ Residence } & Urban & 167 & 39.8 \\
\hline & Rural & 253 & 60.2 \\
\hline \multirow[t]{4}{*}{ Birth order } & First & 183 & 43.6 \\
\hline & Second & 102 & 24.3 \\
\hline & Third & 60 & 14.3 \\
\hline & 4 or more & 75 & 17.9 \\
\hline \multirow[t]{3}{*}{ Ethnicity } & Oromo & 395 & 94.0 \\
\hline & Amhara & 12 & 2.9 \\
\hline & Others* & 13 & 3.1 \\
\hline \multirow[t]{3}{*}{ Religion } & Muslim & 384 & 91.4 \\
\hline & Orthodox & 24 & 5.7 \\
\hline & Others* & 12 & 2.8 \\
\hline Family monthly Income & $1562.5(S D \pm 2769.8)$ & & \\
\hline \multirow[t]{6}{*}{ Educational status } & Unable to read and write & 168 & 40.0 \\
\hline & Read and write & 81 & 19.3 \\
\hline & Primary school (1-8) & 112 & 26.7 \\
\hline & Secondary school (9-12) & 49 & 11.7 \\
\hline & Diploma & 6 & 1.4 \\
\hline & Degree and above & 4 & 1.0 \\
\hline \multirow[t]{4}{*}{ Marital status } & Single & 30 & 7.1 \\
\hline & Married & 345 & 82.1 \\
\hline & Divorced & 12 & 2.9 \\
\hline & Widowed & 33 & 7.9 \\
\hline \multirow[t]{6}{*}{ Occupational status } & Farmer & 219 & 52.1 \\
\hline & Merchant & 61 & 14.5 \\
\hline & Daily laborer & 18 & 4.3 \\
\hline & Housewife & 100 & 23.8 \\
\hline & Private employed & 2 & 0.5 \\
\hline & Government employed & 20 & 4.8 \\
\hline
\end{tabular}

*Other religion includes Wakefata and Catholic *Other Ethnicity includes Kaffa, Yem, Guraghe 
$(407,96.9 \%)$ and $(403,96.0 \%)$ of the study participants, respectively (Table 2).

\section{Knowledge of the respondents regarding the cause and treatments of mental health problems}

Among the causes of mental illness, the most significant responses were brain dysfunction $(390,92.9 \%)$, too much worry $(388,92.4 \%)$, accident or injury $(357,85.0 \%)$, and conflict in marriage or family $(364,86.7 \%)$. Conversely, mental illness was attributed to possession by evil spirits, God's punishment, and witchcraft by $(368,87.6 \%),(321$, $76.4 \%),(259,61.7 \%)$ of the respondents, respectively (Table 3).

\section{Overall knowledge level of the study participants}

The median overall knowledge score value was 33 $(\mathrm{SD} \pm 3.55)$, with the minimum and maximum values of 19 and 42 out of 42 knowledge items. Calculating the proportion of the study population with a cutoff score below and above median score, the overall knowledge score showed $(188,44.8 \%)$ respondents had inadequate knowledge towards mental health problems.

\section{Predictors of knowledge regarding mental health problems}

Variables such as sex, age, residence, birth order, family monthly income, educational status, marital status, occupational status were entered in the bivariate logistic regression analysis, and sex, residence, and educational level were found to have an association at $P$-value $<0.25$. Finally, multivariate logistic regression analysis revealed, respondents who were able to read and write were $64 \%$ less likely to have adequate knowledge compared to those who were with secondary school and above educational status $(\mathrm{AOR}=0.34,95 \% \mathrm{CI}(0.16-0.69))$ (Table 4).

\section{Discussion}

In the current study, nearly half of the respondents had inadequate knowledge regarding mental health and mental health problems. This finding is consistent with the studies conducted in Nigeria [37, 38, 53, 54], Tanzania [41], Southern India [28], among residents of Gimbi town, Ethiopia [9], Denmark [40], Lebanon [30], and Saudi Arabia [55]. Additionally, a report of the Ethiopian public health association expert group report indicates, limited knowledge of mental health problems is prevalent

Table 2 Knowledge of the respondents towards mental health and mental health problems at Jimma Zone, Seka woreda South-west Ethiopia, March 2020

\begin{tabular}{|c|c|c|c|c|}
\hline Variables & Characteristics & Response & Frequency & Percentage \\
\hline Psychiatric disorders are a kind of medical disorders & & Yes & 404 & 96.2 \\
\hline Psychiatric disorders are contagious diseases & & Yes & 75 & 17.9 \\
\hline Recovered psychiatric patients are employed productively & & Yes & 303 & 72.1 \\
\hline Psychiatric disorders are treatable & & Yes & 362 & 86.2 \\
\hline People with severe mental health problems can fully recover & & Yes & 88 & 20.9 \\
\hline Leaving alone is the treatment for mental illness & & Yes & 138 & 32.9 \\
\hline \multirow[t]{12}{*}{ Which are symptoms of mental illness } & Irritability & Yes & 352 & 83.8 \\
\hline & Talking/laughing alone & Yes & 407 & 96.9 \\
\hline & Wandering & Yes & 393 & 93.6 \\
\hline & Excessive and unusual happiness & Yes & 339 & 80.7 \\
\hline & Strange/unusual behavior & Yes & 403 & 96.0 \\
\hline & Excessive Feeling sad, tearful & Yes & 376 & 89.5 \\
\hline & Aggression/violence & Yes & 401 & 95.5 \\
\hline & Hearing and seeing things that are not there & Yes & 389 & 92.6 \\
\hline & Lack of sleep & Yes & 376 & 89.5 \\
\hline & Talkativeness & Yes & 394 & 93.8 \\
\hline & Trying to kill oneself & Yes & 386 & 91.9 \\
\hline & Isolating oneself & Yes & 401 & 95.5 \\
\hline Older people may develop mental disorders & & Yes & 371 & 88.3 \\
\hline Children may develop mental disorders & & Yes & 332 & 79.0 \\
\hline Women may develop mental disorders as equal to male & & Yes & 265 & 63.1 \\
\hline $\begin{array}{l}\text { Lower socioeconomic class increases the risk of having } \\
\text { psychiatric disorders }\end{array}$ & & Yes & 310 & 73.8 \\
\hline
\end{tabular}


Table 3 Knowledge of the respondents towards mental health and mental health problems at Jimma Zone, Seka woreda South-west Ethiopia, March 2020

\begin{tabular}{|c|c|c|c|c|}
\hline Variables & Characteristics & Response & Frequency & Percentage \\
\hline \multirow[t]{14}{*}{ Metal illness is due to } & Genetic reasons & Yes & 116 & 27.6 \\
\hline & Stress/tension & Yes & 377 & 89.8 \\
\hline & Accident/injury & Yes & 357 & 85.0 \\
\hline & Brain functional abnormality & Yes & 390 & 92.9 \\
\hline & Family events/conflict & Yes & 350 & 83.3 \\
\hline & Conflict in marriage or family & Yes & 364 & 86.7 \\
\hline & Worrying too much & Yes & 388 & 92.4 \\
\hline & Neurotransmitter imbalances & Yes & 271 & 64.5 \\
\hline & witchcraft & Yes & 259 & 61.7 \\
\hline & God's punishment for past sins & Yes & 321 & 76.4 \\
\hline & Evil spirit possession & Yes & 368 & 87.6 \\
\hline & Personal weakness & Yes & 240 & 57.1 \\
\hline & Poor nutrition & Yes & 210 & 50.0 \\
\hline & Polluted atmosphere & Yes & 149 & 35.5 \\
\hline \multirow[t]{3}{*}{ Mental illness can be treated } & Traditional & Yes & 205 & 48.8 \\
\hline & Religious & Yes & 272 & 64.8 \\
\hline & Medical & Yes & 337 & 80.2 \\
\hline $\begin{array}{l}\text { professional advice or counseling can be an effective treatment for people } \\
\text { with mental illnesses }\end{array}$ & & Yes & 256 & 61.0 \\
\hline Medication can be an effective treatment for people with mental illnesses & & Yes & 358 & 85.2 \\
\hline Mental illness requires treatment from the psychiatric hospital & & Yes & 378 & 90 \\
\hline Mental illness can be successfully managed at home by families & & Yes & 209 & 49.8 \\
\hline Mental illness should be managed by witchdoctors & & Yes & 215 & 51.2 \\
\hline Mental illness can be cured by marriage & & Yes & 207 & 49.3 \\
\hline
\end{tabular}

Responses only "Yes" or "No"

in the community [63]. The overall inadequate knowledge across all the studies could reflect that despite the high prevalence of mental health problems that affect every community across the world, less emphasis and attention has been given to design appropriate strategies to fill the knowledge gap.

This study finding has revealed a blend of biological, psychological, and cultural factors are the cause mental illness. This result was supported by the studies done in Nigeria [37-39], northern Ethiopia [13], and Denmark [40]. In contrary to this, biological factors were reported as the main causes of mental illness in the studies conducted in Tanzania [41], Eretria [38], and Saudi Arabia [42]. Additionally, religious and cultural explanations for the causes of mental illness were reported by the studies done in South Africa [43], Agro, Gimbi town, and Borana Ethiopia [44-46], Nigeria [36], and Pakistan [47]. The differences in the description of causes of mental illness across different societies could be explained by the socioeconomic, literacy status, urban-rural study setting differences across the studies.

Nearly all the study participants described talking or laughing alone and showing strange or unusual behaviors were the manifestations of mental illness. This is in line with the studies done in northern Nigeria [39, 54, 64], Jeddah city Saudi Arabia [42], Agaro town, Ethiopia [52], and India [65]. This finding could reflect the similarities of mental health problem manifestations across different geographical locations of the world.

More than three-quarters of the respondents reported recovered psychiatric patients are employed productively. This finding is supported by the study done in north Ethiopia [13]. Contrary to this, the studies were done in Nigeria [37] and Tanzania [41] reported that a mentally ill patient could not be productive even after recovery. This could show that the study respondents are optimistic about the recovery of patients with mental health problems.

In this study, most of the respondents mentioned the combination of medical, religious, and traditional treatments for mental illness, and this is consistent with the studies done in Eritrea [48], Saudi Arabia [49], Nigeria [39], and Ethiopia [5]. In contrast to this, the studies were done in Tanzania [41], Saudi Arabia [42], Slovak Republic, and Russia [50], New Zealand [51], South Africa [43], Ethiopia [13, 52], and India [45] revealed 
Table 4 Factors associated with mental health and mental health problems knowledge of the respondents at Jimma Zone, Seka woreda, South-west Ethiopia, March 2020

\begin{tabular}{|c|c|c|c|c|c|}
\hline \multirow[t]{3}{*}{ Variables } & \multirow[t]{3}{*}{ Category } & \multicolumn{2}{|c|}{$\begin{array}{l}\text { Knowledge toward mental health } \\
\text { and mental problems }\end{array}$} & \multirow[t]{3}{*}{ COR $(95 \% \mathrm{Cl})$} & \multirow[t]{3}{*}{ AOR $(95 \% \mathrm{Cl})$} \\
\hline & & Inadequate & Adequate & & \\
\hline & & Frequency (\%) & Frequency (\%) & & \\
\hline \multirow[t]{2}{*}{ Sex } & Male & $94(49.5)$ & $96(50.5)$ & $0.70(0.47-1.04)^{*}$ & \\
\hline & Female & $94(40.9)$ & $136(59.1)$ & 1 & \\
\hline \multirow[t]{4}{*}{ Age } & $18-28$ & $40(40.4)$ & $59(59.6)$ & $1.18(0.63-2.23)$ & \\
\hline & 29-39 & $88(49.7)$ & $89(50.3)$ & $0.81(0.46-1.44)$ & \\
\hline & $40-49$ & $31(39.2)$ & $48(60.8)$ & $0.81(0.64-2.42)$ & \\
\hline & $>50$ & $29(44.6)$ & $36(55.4)$ & 1 & \\
\hline \multirow[t]{2}{*}{ Marital status } & Unmarried & $36(48.0)$ & $39(52.0)$ & $0.85(0.51-1.40)$ & \\
\hline & Married & $152(44.1)$ & $193(55.9)$ & 1 & \\
\hline \multirow[t]{2}{*}{ Residence } & Urban & $83(49.7)$ & $84(50.3)$ & $1.39(0.94-2.06)^{*}$ & \\
\hline & Rural & $105(41.5)$ & $148(58.5)$ & 1 & \\
\hline \multirow[t]{4}{*}{ Birth order } & First & $84(45.9)$ & $99(54.1)$ & $0.78(0.45-1.35)$ & \\
\hline & Second & $49(48.0)$ & $53(52.0)$ & $0.72(0.39-1.31)$ & \\
\hline & Third & $25(41.7)$ & $35(58.3)$ & $0.93(0.46-1.86)$ & \\
\hline & 4th or more & $30(40.0)$ & $45(60.0)$ & 1 & \\
\hline \multirow[t]{4}{*}{ Family monthly Income } & $<1000$ & $77(40.1)$ & $115(59.9)$ & $1.04(0.38-2.86)$ & \\
\hline & $1001-2999$ & $95(51.1)$ & $91(48.9)$ & $0.67(0.24-1.83)$ & \\
\hline & 3000-4999 & $9(36.0)$ & $16(64.0)$ & $0.24(0.35-4.40)$ & \\
\hline & $>5000$ & $7(41.2)$ & $10(58.8)$ & 1 & \\
\hline \multirow[t]{4}{*}{ Educational Level } & Unable to read and write & $63(37.5)$ & $105(62.5)$ & $1.14(0.62-2.09)$ & $0.95(0.51-1.78)$ \\
\hline & Read and write & $51(63.0)$ & $30(37.0)$ & $0.40(0.20-0.80)^{*}$ & $0.34(0.16-0.69)^{* *}$ \\
\hline & Primary school (1-8) & $50(44.6)$ & $62(55.4)$ & $0.61(0.85-0.44)$ & $0.77(0.40-1.48)$ \\
\hline & Secondary school (9-12) and above & $24(40.7)$ & $35(59.3)$ & 1 & 1 \\
\hline \multirow[t]{4}{*}{ Occupational status } & Farmer & $95(43.4)$ & $124(56.6)$ & $0.98(0.61-1.58)$ & \\
\hline & Merchant & $30(49.2)$ & $31(50.8)$ & $0.78(0.41-1.47)$ & \\
\hline & Housewife & $20(50.0)$ & $20(50.0)$ & $0.75(0.36-1.57)$ & \\
\hline & Employed & $43(43.0)$ & $57(57.0)$ & 1 & \\
\hline
\end{tabular}

1, Reference

${ }^{*} P$-value $<0.25,{ }^{* *}$ Variables significant at $P$ value $<0.05$

medical management (medication and counseling) was identified as the first option for treatment of mental illnesses. Whereas, the studies conducted in Southern India [28] and Nigeria [38, 53, 54] have shown traditional treatments (Cultural or religious) as primary choices of treatment. Different factors such as literacy status, availability of the mental health treatment services, distance and affordability of mental health service, quality of mental health service, mental health professional availability, and religious influence may contribute to the selection of treatment options in the community.

Almost eighty-five percent of this study participants stated that mental illness is treatable; this is consistent with the studies done in Eretria, Nigeria, India [38,
45, 48], and New Zealand [51]. These findings could confirm that despite the differences in the preference of treatment options, the community is hopeful and believes mental illness better treatment outcomes. However, half of the respondents reported that mental illness could be cured by marriage in the current study. A similar finding was found in the research done in Southern India [28]. This report could reflect the community knowledge gap regarding mental health problem treatments.

In this study, the educational level of the participants was found associated with community knowledge about mental health problems. This finding is supported by the studies done in Ethiopia [9, 13] and China [66]. On the other hand, the studies were done in Saudi Arabia [55, 
67], and Lebanon [30] found no association between the community knowledge about mental health problems and educational level.

\section{Conclusion}

Knowledge of mental illness among the general public was relatively poor and significantly associated with educational status. This suggests the need for a strong emphasis on public education to improve the mental health literacy status of the general public.

\section{Abbreviations}

AOR: Adjusted odds ratio; Cl: Confidence interval; MAKS: Mental health knowledge schedule; SD: Standard deviation; SPSS: Statistical package for social science studies; US: United States; WHO: World Health Organization.

\section{Supplementary Information}

The online version contains supplementary material available at https://doi. org/10.1186/s40359-021-00607-5.

Additional file 1. Appendix listing survey questions.

\section{Acknowledgements}

We want to express our deepest gratitude to Jimma University for funding this study and all who supported us in accomplishing this study.

\section{Authors' contributions}

TY and YK were involved in designing the study, data collection, supervision, data processing, cleaning, analysis, interpretation of the results, and drafting the manuscript. AL, AS, TG, BZ, AG, GM were participating in methodological correction, supporting statistical analysis, interpreting the results, and revising the manuscript. All the authors read and approved the manuscript.

\section{Funding}

Jimma University funded the study. The university had no role in the design of the study; in the collection, analysis, and interpretation of the data, and in writing or reviewing of the manuscript.

\section{Availability of data and materials}

The datasets used and/or analyzed during the current study are available from the corresponding author on reasonable request.

\section{Declarations}

\section{Ethics approval and consent to participate}

The study was reviewed and approved by the Institutional Review Board (IRB) of Jimma University institute of health (IHRPGD/584/2019). An official letter of support was written and approved by the Oromia health bureau, Jimma zone health bureau. A subsequent support letter was obtained from the Seka chekorsa district health office before the commencement of data collection. Respondents were briefed on the study objectives and were assured of the anonymity of their participation. The study participation was voluntary and written informed consent was obtained from each respondent. Informed consent was taken from a legally authorized representative for individuals who were unable to read and write. The study was conducted under the Helsinki declaration.

\section{Consent for publication}

Not applicable.

\section{Competing interests}

The authors declare that they have no competing interests.

\section{Author details}

${ }^{1}$ Department of Psychiatry, Jimma University, Po Box 378, Jimma, Oromia, Ethiopia. ${ }^{2}$ School of Nursing and Midwifery, Jimma University, Jimma, Oromia, Ethiopia. ${ }^{3}$ Department of Environmental Health Sciences and Technology, Jimma University, Jimma, Oromia, Ethiopia. ${ }^{4}$ Department of Health, Behavior, and Society, Jimma University, Jimma, Oromia, Ethiopia. ${ }^{5}$ Department of Biostatistics and Epidemiology, Jimma University, Jimma, Oromia, Ethiopia. ${ }^{6}$ Department of Health Policy and Management, Jimma University, Jimma, Oromia, Ethiopia.

Received: 1 December 2020 Accepted: 1 July 2021

Published online: 14 July 2021

\section{References}

1. WHO (World Health Organization). Investing in mental health. 2003;3-49.

2. St E, Church M, Ababa A. Magnitude of mental illness and associated factors among holy water users. J Psychiatry. 2015;18(4):1-5.

3. Haile YG, Alemu SM, Habtewold TD. Common mental disorder and its association with academic performance among Debre Berhan University students. Ethiopia Int J Ment Health Syst. 2017;11(34):1-11.

4. Ahmed E, Merga H, Alemseged F. Knowledge, attitude, and practice towards mental illness service provision and associated factors among health extension professionals in Addis Ababa. Ethiopia Int J Ment Health Syst. 2019;13(5):1-9.

5. Teferra S, Shibre T. Perceived causes of severe mental disturbance and preferred interventions by the Borana semi-nomadic population in southern Ethiopia: a qualitative study. BMC Psychiatry. 2012;12(79):1-9.

6. World Health Organization. Mental Health Gap Action Programme - Scaling up care for mental, neurological, and substance use disorders. World Heal Organ; 2008.

7. Monteiro NM. Addressing mental illness in Africa: global health challenges and addressing mental illness in Africa: global health challenges and local opportunities. Commun Psychol Glob Perspect. 2015;1(2):78-95.

8. Salve H, Goswami K, Sagar R, Nongkynrih B, Sreenivas V. Perception and attitude towards mental illness in an urban community in South Delhi-a community-based study. Indian J Psychol Med. 2013;35(2):154-8.

9. Benti M, Ebrahim J, Awoke T, Yohannis Z, Bedaso A. Community perception towards mental illness among residents of Gimbi Town. Western Ethiopia Psychiatry J. 2016;2016:1-8.

10. Jilowa CS, Chandravanshi G, Mahawer B, Jain M. Impact of psychiatry training on attitude of medical students toward mental illness and psychiatry. IOSR J Dent Med Sci. 2016;15(4):18-22.

11. Thornicroft G, Deb T, Henderson C. Community mental health care worldwide: current status and further developments. Psychiatr Serv. 2016;52(7):276-86.

12. Sujaritha V, Partheeban M, Thiviya T, Sowmiya M. Attitude towards mental illness among doctors and nurses in tertiary care original research article attitude towards mental illness among doctors and nurses in a tertiary care center, Pondicherry. India Int J Res Med Sci. 2017;5(7):3059-64.

13. Abbay AG, Mulatu AT, Azadi H. Community knowledge, perceived beliefs and associated factors of mental distress : a case study from Northern Ethiopia. Int J Environ Res Public Heal. 2018;15:1-22.

14. Article CR. Mental illness: global African and Ethiopian perspectives. EC Psychol Psychiatry. 2017;4(3):107-10.

15. Denise Saint Arnault. Cultural determinants of help-seeking: a model for research and practice. Res Theory Nurs Pr [Internet]. 2014;23(1):1-7. Available from: https://www.ncbi.nlm.nih.gov/pmc/articles/PMC3624763/pdf/ nihms412728.pdf.

16. Laraib A, Sajjad A, Sardar A, Wazir MS, Nazneen Z. Perspective about mental illnesses: a survey of health care providers of abbottabad. J Ayub Med Coll Abbottabad. 2018;30(1):97-102.

17. Belayneh Z, Abebaw D, Amare T, Haile K, Abebe Z. Perception regarding the causes of schizophrenia and associated factors among Feresbet district residents: a community-based study. BMC Public Health. 2019;19(1):1-7

18. Ndetei DM. Knowledge, attitude and practice (KAP) of mental illness among staff in general medical facilities in Kenya: practice and policy implications. Afr J Psychiatry. 2016;2011(14):225-35. 
19. Mutiso V. Knowledge, attitude and practice (KAP) of mental illness among staff in general medical facilities in Kenya: practice and policy implications. Afr J Psychiatry. 2011;14:225-35.

20. Oaks T, Delhi N. Perceptions of mental and physical illnesses in north-western. J Health Psychol. 1999;4(4):531-49.

21. Holmes EP, Corrigan PW, Williams P, Conor J, Kubiak MA. Changing attitudes about schizophrenia. Schizophr Bull. 1999;25(3):447-56.

22. Park T. Familiarity with and social distance from people who have serious mental illness. Psychiatr Serv. 2001;52(7):5-10.

23. Van Der HL, Wright P. Perceptions of mental health and help-seeking behavior in an urban community in Vietnam : an explorative study. Commun Ment Heal J. 2011;47:574-82.

24. People Y. Mental health help-seeking behaviors in young adults. Br J Gen Pract. 2017;11-2.

25. Kerebih H. Pattern of help-seeking behavior for common mental disorders among urban residents in southwest Ethiopia. Qual Prim Care. 2017;25(4):208-16.

26. Rijal A. Mental health situation in Nepal and priorities for interventions. Heal Prospect J Public Heal. 2018;17:10-2.

27. Nal O, Search RE. Community attitudes toward people with schizophrenia. Can J Psychiatry. 2001;46(April):245-52.

28. Ganesh K. Knowledge and attitude of mental illness among the general public of southern India. Natl J Commun Med. 2011;2(1):175-8.

29. Jorm AF. Mental health literacy public knowledge and beliefs about mental disorders. Br J Psychiatry. 2000;177:396-401.

30. Doumit CA, Haddad C, Id HS, Salameh P, Akel M, Obeid S, et al. Knowledge, attitude and behaviors towards patients with mental illness : Results from a national Lebanese study. PLOS ONE. 2019;14(9):1-16.

31. Yuan Q, Picco L, Chang S, Abdin E, Chua BY, Ong S, et al. Attitudes to mental illness among mental health professionals in Singapore and comparisons with the general population. PLoS ONE. 2017;12(11):1-14.

32. Brockington IF, Hall P, Levings J, Murphy C. The community's tolerance of the mentally ill. Br J Psychiatry. 1993;162(1):93-9.

33. Wei Y, Mcgrath PJ, Hayden J, Kutcher S. Mental health literacy measures evaluating knowledge, attitudes, and help-seeking: a scoping review. BMC Psychiatry. 2015;15(291):1-20. https://doi.org/10.1186/s12888-015-0681-9.

34. Hansson L. Changes in attitudes, intended behavior, and mental health literacy in the Swedish population 2009-2014: an evaluation of a national anti-stigma program. Acta Psychiatry Scand. 2016;134(446):71-9.

35. Angermeyer MC, Holzinger A, Carta MG, Schomerus G. Biogenetic explanations and public acceptance of mental illness: a systematic review of population studies. Br J Psychiatry. 2011;199:367-72.

36. Okpalauwaekwe U, Mela M, Oji C. Knowledge of and attitude to mental illnesses in Nigeria: a scoping review. Integr J Glob Health. 2017;1(5):1-14.

37. Gureje OYE, Lasebikan VO, Ephraim-oluwanuga O, Oluwanuga EA, Olley BO, Kola L. Community study of knowledge of and attitude to mental illness in Nigeria. Br J Psychiatry. 2005;186:436-41.

38. Effiong $\mathrm{H}$, Idung $\mathrm{AU}$, lyanam VE. Knowledge, attitudes, and perceptions about mental illness in Ekom Iman community in Akwa Ibom. AJMAH. 2019;17(3):1-9.

39. Zever ISY. Assessment of relatives beliefs and attitude on mental illness. Ann Med Health Sci Res. 2017;7:110-5.

40. We AL. Community knowledge of mental illness and reaction to mentally ill people. Br J Psychiatry. 1996;168:191-8.

41. Benedicto M, Mndeme E, Mwakagile DSM, Tumbwene E. Community knowledge, attitudes and perception towards mental illness in Dodoma municipality, Tanzania. ARC J Public Health Commun Med. 2016;1(3):10-8.

42. Aljedaani SM. Adults' knowledge, attitudes, and willingness to interact with patients suffering from mental illness in Jeddah City. J Am Psychiatr Nurses Assoc. 2019;25(5):360-75.

43. Hugo CJ, Boshoff DEL, Traut A, Stein NZDJ. Community attitudes toward and knowledge of mental illness in South Africa. Soc Psychiatry Psychiatr Epidemio. 2003;2020(38):715-9.

44. Deribew A, Tamirat YS. How are mental health problems perceived by a community in Agaro town? Ethiop J Heal Dev. 2005;19(2):153-9.

45. Bagchi A, Sarkar P, Basu R. Knowledge, attitude and practice towards mental health illnesses in an urban community in West Bengal: a community-based study. Int J Community Med Public Health. 2020;7(3):1078-83.
46. Teferra S, Shibre T. Perceived causes of severe mental disturbance and preferred interventions by the Borana semi-nomadic population in southern Ethiopia: a qualitative study. BMC Psychiatry. 2012;12:1-9.

47. Shafiq S. Perceptions of Pakistani community towards their mental health problems: a systematic review. Glob Psychiatry. 2020;3(1):1-23.

48. Adgoy ET, Habtemariam R. Cross-sectional study on community knowledge and perception on mental illness among residents of sub-zoba serejaka (Embaderho and Geshinashim villages). Eritrea MOJ Public Health. 2018;7(3):3-7.

49. Alhabeeb AA, Alasmari SS, Alduraihem RA, Qureshi NA. Mental health awareness phone polling survey: focus on community knowledge, attitude and practice. Saudi Arabia Int Neuropsychiatr Dis J. 2019;13(2):1-14.

50. Angermeyer MC, Breier P, Dietrich S, Kenzine D, Matschinger H. Public attitudes toward psychiatric treatment An international comparison. Soc Psychiatry Epidemiol. 2005;40:855-64.

51. Deverick Z, Russell L, Hudson S. Attitudes of adults towards people with experience of mental distress: results from the 2015 New Zealand Mental Health Monitor; 2017.

52. Deribew A, Tamirat YS. How are mental health problems perceived by a community in Agaro town ? Ethiop J Health Dev. 2014;16(2):153-9.

53. Agofure $\mathrm{O}, \mathrm{Or} \mathrm{O}$, Is $\mathrm{U}$. Knowledge and perception of mental disorders among relatives of mentally ill persons in a rural community in South-South Nigeria. J Commun Med Prim Heal Care. 2019;31(2):66-77.

54. Kabir M, Iliyasu Z, Abubakar IS, Aliyu MH. Perception and beliefs about mental illness among adults in Karfi village, northern Nigeria. BMC Int Health Hum Rights. 2004:4(3):2-6.

55. Abolfotouh MA, Almutairi AF, Almutairi Z, Salam M, Alhashem A, Adlan AA, et al. Attitudes toward mental illness, mentally ill persons, and help-seeking among the Saudi public and sociodemographic correlates. Psychol Res Behav Manag. 2019;12:45-54.

56. Mulatu MS. Perceptions of mental and physical illnesses in North-western Ethiopia: causes, treatments, and attitudes. J Health Psychol. 1999;4(4):53149. https://doi.org/10.1177/135910539900400407.

57. Federal Democratic Republic of Ethiopia Central Statistical Agency Population Projection of Ethiopia for All Regions At Wereda Level from 2014-2017; 2013.

58. Seka Chekorsa (woreda)—Wikipedia.

59. Sambo L, Chatora R, Goosen E. Tools for assessing the operationality of district health systems. WHO. 2003;1-112.

60. Evans-Lacko S, Little K, Meltzer H, Rose D, Rhydderch D, Henderson C, Thornicroft G. Development and psychometric properties of the Mental Health Knowledge Schedule. Can J Psychiatry. 2010;55(7):440-448

61. Henderson C, Evans-Lacko S, Thornicroft G. Mental illness stigma, help-seeking, and public health programs. Am J Public Health. 2013;103(5):777-80.

62. Wong PWC, Arat G, Ambrose MR, Qiuyuan KX, Borschel M, Wong PWC, et al. Evaluation of a mental health course for stigma reduction: a pilot study evaluation of a mental health course for stigma reduction: a pilot study. Cogent Psychol. 2019;6(1):1-12.

63. Alem A, Desta M, Araya M. Mental health in Ethiopia EPHA Expert Group report.

64. Effiong $\mathrm{JH}$, Idung $\mathrm{AU}$, lyanam VE. Knowledge, attitudes, and perceptions about mental illness in Ekom Iman Community in Akwa Ibom State, SouthSouth Nigeria. Asian J Med Heal. 2019; 1-9.

65. Sneha CR, Reddy MM, Jagadish S. Awareness and attitude toward mental illness among a rural population in Kolar. Indian J Soc Psychiatry. 2019;35(1):69-74

66. Li J, Zhang M, Zhao L, Li W, Mu J, Zhang Z. Evaluation of attitudes and knowledge toward mental disorders in a sample of the Chinese population using a web-based approach. BMC Psychiatry. 2018;18(367):1-8.

67. Mahmoud MA. Knowledge and awareness regarding mental health and barriers to seeking psychiatric consultation in Saudi Arabia. Asian J Pharm Res Health Care. 2018;10(4):109-16.

\section{Publisher's Note}

Springer Nature remains neutral with regard to jurisdictional claims in published maps and institutional affiliations. 